\title{
Comparative Psychology
}

National Cancer Institute

\section{Source}

National Cancer Institute. Comparative Psychology. NCI Thesaurus. Code C17029.

The study of animal behavior, with an emphasis on the similarities and differences that relate to evolutionary and developmental processes. 